\title{
MÃO DE OBRA QUALIFICADA NA CIDADE DE FORMIGA-MG: UMA COMPARAÇÃO ENTRE OS CURSOS OFERECIDOS PELAS IES E A DEMANDA DAS EMPRESAS DA CIDADE ${ }^{1}$
}

\author{
Nágila Vilela ${ }^{2}$ \\ Adriano Olímpio Tonelli ${ }^{3}$ \\ Izabele Figueiredo Mascarenhas ${ }^{4}$
}

\begin{abstract}
RESUMO
A falta de mão de obra qualificada é um problema ocorrente na economia brasileira. Tal dificuldade é intensificada nas micro, pequenas e médias empresas (MPEs), muitas vezes por serem empresas recentes e sem planejamento prévio. O presente estudo objetivou explorar a relação entre a oferta de cursos superiores na cidade de Formiga-MG e a demanda das empresas locais por profissionais qualificados. A pesquisa, de caráter qualitativo e exploratório, teve a participação de 56 empresas da cidade, sendo 36 de micro e pequeno porte, atuantes em diferentes segmentos. Os resultados revelaram que as empresas optam por contratar profissionais com baixo nível de escolaridade (inferior a 11 anos), mas buscam características de profissionais qualificados. Adicionalmente menos da metade das empresas entrevistadas mencionou admitir profissionais com nível superior, e apenas uma admite empregar quem possui pós-graduação. Esse fato pode ser consequência da acomodação da economia brasileira em relação a baixos padrões de qualificação de mão de obra e produtividade.
\end{abstract}

Palavras chave: Qualificação profissional. Mercado de trabalho. Ensino Superior.

\section{INTRODUÇÃO}

As Micro e Pequenas Empresas (MPEs) têm apresentado um papel fundamental no desenvolvimento da economia brasileira ao longo das últimas décadas. De acordo com um levantamento realizado pelo Serviço Brasileiro de Apoio às Micro e Pequenas Empresas -

\footnotetext{
${ }^{1}$ Como citar este artigo:

VILELA, N.; TONELLI, A. O.; MASCARENHAS, I. F. Mão de obra qualificada na cidade de Formiga-MG: uma comparação entre os cursos oferecidos pelas IES e a demanda das empresas da cidade. ForScience: revista científica do IFMG, Formiga, v. 4, n. 2, e00196, jul./dez. 2016.

2 Mestranda em Administração na linha de Estratégia e Análise Organizacional na Universidade Federal do Paraná. (http://lattes.cnpq.br/6442991737466181). E-mail: nagilavilela@gmail.com.

${ }^{3}$ Mestre em Administração pela Universidade Federal de Lavras (UFLA), especialista em MBA Executivo em Governança de TI pela UFLA e professor do Instituto Federal de Minas Gerais - Campus Formiga. (http://lattes.cnpq.br/1462078527557508). E-mail: adriano.tonelli@ifmg.edu.br.

4 Especialista em Administração Hospitalar pela Universidade de Ribeirão Preto, graduação em Administração pela Universidade Estadual de Montes Claros. Atualmente é servidora pública no Instituto Federal de Minas Gerais - Campus Formiga. (http://lattes.cnpq.br/1626571772980146).

E-mail: izabele.mascarenhas@ifmg.edu.br.
}

ForSci.: r. cient. IFMG, Formiga, v. 4, n. 2, e00196, jul./dez. 2016. 
VILELA, N.; TONELLI, A. O.; MASCARENHAS, I. F. Mão de obra qualificada na cidade de Formiga-MG: uma comparação entre os cursos oferecidos pelas IES e a demanda das empresas da cidade

SEBRAE, no Brasil, são criados mais de um milhão de novos empreendimentos formais por ano. Desse total, mais de 99\% são provenientes das MPEs. Em termos quantitativos, em 2011 as MPEs geraram cerca de $27 \%$ do Produto Interno Bruto (PIB) do país, 52\% dos empregos com carteira assinada e $34 \%$ dos salários pagos (SERVIÇO BRASILEIRO DE APOIO ÀS MICRO E PEQUENAS EMPRESAS, 2014a; SERVIÇO BRASILEIRO DE APOIO ÀS MICRO E PEQUENAS EMPRESAS, 2014b).

No entanto, apesar dos números expressivos, as MPEs que atuam, "em sua maioria, em setores intensivos em trabalho" (FRACALANZA; FERREIRA, 2012, p.89) vêm sofrendo com a escassez de mão de obra qualificada. Em pesquisas realizadas pela Fundação Dom Cabral $(2010 ; 2013)$, observou-se que cerca de 90\% das empresas apresentaram problemas na contratação de pessoas devido à falta de profissionais capacitados.

Segundo Dias (2013), a formação de profissionais capacitados na economia está intimamente ligada à educação superior. A graduação em andamento ou concluída, assim como a frequência em cursos de especialização, mestrado e doutorado qualificam os indivíduos. A diferenciação entre ensino fundamental, médio e o superior é evidente, visto que os ensinamentos no terceiro grau orientam os profissionais em conhecimentos específicos, enquanto o primeiro e segundo graus propõem conhecimentos generalizados, salvo nos cursos técnicos (DIAS, 2013).

Em Formiga, cidade localizada na região centro-oeste de Minas Gerais, a economia é fundamentada no setor de serviço/comércio, que representa cerca de $72,3 \%$ do PIB total da cidade (INSTITUTO BRASILEIRO DE GEOGRAFIA E ESTATÍSTICA, 2016). A estrutura produtiva é composta por cerca de 94\% de MPEs (CONFEDERAÇÃO NACIONAL DO COMÉRCIO DE BENS, SERVIÇOS E TURISMO, 2016) e a cidade busca nas parcerias com a Câmara de Dirigentes Lojistas de Formiga (CDL) e Associação Comercial, Industrial, de Serviços e Agronegócios de Formiga (ACIF) condições para as MPEs se manterem competitivas. Ademais, em uma sociedade com mercado de trabalho dinâmico e oscilante, é importante que as Instituições de Ensino Superior (IES) formem profissionais com as habilidades que as empresas necessitam, com o perfil esperado e demandado por elas.

Para oferecer ao mercado a mão de obra capacitada necessária para as empresas, a cidade de Formiga conta com três instituições de ensino superior: Centro Universitário de Formiga (UNIFOR), Instituto Federal de Minas Gerais - Campus Formiga (IFMG) e Universidade Aberta do Brasil (UAB). 
VILELA, N.; TONELLI, A. O.; MASCARENHAS, I. F. Mão de obra qualificada na cidade de Formiga-MG: uma comparação entre os cursos oferecidos pelas IES e a demanda das empresas da cidade

O UNIFOR oferece 22 cursos de graduação nas áreas: Ciências Agrárias, Ciências Biológicas, Ciências da Saúde, Ciências Exatas e da Terra, Ciências Sociais Aplicadas e Engenharias. O IFMG conta com 5 cursos superiores nas áreas Ciências Exatas e da Terra, Ciências Sociais Aplicadas e Engenharias, e, por fim, os 6 cursos oferecidos pela UAB estão dispostos nas seguintes áreas do conhecimento: Ciências Biológicas, Ciências Humanas e Ciências Sociais Aplicadas.

Diante desse contexto, surge a seguinte questão de pesquisa: qual é, na visão do empresariado, a demanda por mão de obra na cidade de Formiga-MG?

A pesquisa justifica-se pelo fato de contribuir tanto para as empresas, quanto para as instituições de ensino superior e os profissionais que estão em busca da inserção no mercado de trabalho formiguense. Para as empresas, porque tiveram oportunidade de expor o perfil profissional almejado; para as IES, pois foram fornecidas informações relevantes para a manutenção e/ou abertura de novos cursos nas três instituições mencionadas e para os profissionais, porque poderão inteirar-se das características profissionais que o mercado demanda.

\section{REFERENCIAL TEÓRICO}

\subsection{Micro, Pequenas e Médias Empresas}

Em um estudo realizado pelo SEBRAE em 2014 a respeito da participação das micro e pequenas empresas na economia brasileira, constatou-se que cerca de 9 milhões de MPEs estão instaladas no Brasil. Mais da metade dos empregos formais são representados por essas empresas e elas já são as principais geradoras de riqueza no comércio brasileiro $(53,4 \%$ do PIB desse setor). Na indústria, a participação das MPEs corresponde a 22,5\% do PIB e no setor de serviços, 36,3\% da produção nacional é originada nos pequenos e médios negócios (SERVIÇO BRASILEIRO DE APOIO ÀS MICRO E PEQUENAS EMPRESAS, 2014a).

Para a classificação das MPEs, dois métodos podem ser adotados: número de pessoas ocupadas na empresa ou receita auferida. A Tabela 1 apresenta a relação entre o porte e o número de pessoas ocupadas em cada tipo de atividade econômica (serviços e comércio e indústria). As empresas que possuem receita de até $\mathrm{R} \$ 3.600 .000,00$ anuais são classificadas como de micro e pequeno porte (SERVIÇO BRASILEIRO DE APOIO ÀS MICRO E PEQUENAS EMPRESAS, 2014b).

ForSci.: r. cient. IFMG, Formiga, v. 4, n. 2, e00196, jul./dez. 2016. 
VILELA, N.; TONELLI, A. O.; MASCARENHAS, I. F. Mão de obra qualificada na cidade de Formiga-MG: uma comparação entre os cursos oferecidos pelas IES e a demanda das empresas da cidade

Tabela 1 - Critério de classificação do porte das empresas por pessoas ocupadas - Brasil - 2014

\begin{tabular}{lll}
\hline \multirow{1}{*}{ Porte } & \multicolumn{2}{c}{ Atividades Econômicas } \\
\cline { 2 - 3 } & \multicolumn{1}{c}{ Serviço e Comércio } & \multicolumn{1}{c}{ Indústria } \\
\hline Microempresa & Até 09 pessoas ocupadas & Até 19 pessoas ocupadas \\
Pequena empresa & De 10 a 49 pessoas ocupadas & De 20 a 99 pessoas ocupadas \\
Média empresa & De 50 a 99 pessoas ocupadas & De 100 a 499 pessoas ocupadas \\
Grande empresa & Acima de 100 pessoas ocupadas & Acima de 500 pessoas ocupadas \\
\hline Fonte: Adaptado de Serviço Brasileiro de Apoio às micro e pequenas empresas (2014b).
\end{tabular}

De acordo com o Instituto Brasileiro de Geografia e Estatística (2003), as principais características das micro e pequenas empresas são:

a) capital empregado limitado;

b) taxas elevadas de natalidade e mortalidade: demografia elevada;

c) frequente presença de proprietários, sócios e funcionários com laços familiares;

d) centralização no poder decisório;

e) confusão entre pessoa física e jurídica;

f) registros contábeis pouco apropriados;

g) contratação direta de mão de obra;

h) emprego de mão de obra pouco ou não qualificada;

i) pouco investimento em inovação tecnológica;

j) dificuldade de acesso ao financiamento de capital de giro;

k) relação de complementaridade e subordinação com empresas de grande porte.

Iarozinski Neto e Caciatori Junior (2006), em um levantamento sobre as principais dificuldades encontradas pelas pequenas e médias empresas (PMEs), consideraram as seguintes dimensões: gestão, ambiente, governo, empreendedorismo, finanças, recursos humanos, tecnologia da informação e produção. Escassez de pessoal altamente qualificado é um problema incluído na dimensão recursos humanos e identificado por Deitos (2002 apud IAROZINSKI NETO; CACIATORI JUNIOR, 2006).

As PMEs são consideradas empresas recentes e sem planejamento prévio. Por esses e por outros motivos, não podem ser vistas como grandes empresas, pois, em tese, essas possuem maior capacidade de lidar com incertezas do ambiente externo, além de possuírem ForSci.: r. cient. IFMG, Formiga, v. 4, n. 2, e00196, jul./dez. 2016. 
conhecimento mais amplo a respeito dos instrumentos de administração. Os escassos mecanismos de proteção das PMEs resultam em problemas financeiros, de gestão, recursos humanos e TI, provocando a morte de uma parcela dessas empresas (IAROZINSKI NETO; CACIATORI JUNIOR, 2006).

\subsection{O mercado de trabalho e o perfil profissional demandado}

O mercado de trabalho é dinâmico e as oscilações entre oferta e demanda por mão de obra estão relacionadas com o crescimento e intervenções econômicas. Com a globalização e os avanços tecnológicos, a demanda por trabalhadores mais qualificados aumenta e, ao mesmo tempo em que cresce o rendimento dos profissionais capacitados, aumenta a desigualdade de salários (CASTELLO BRANCO, 1979).

Em 2013, o núcleo de Logística, Supply Chain e Infraestrutura da Fundação Dom Cabral realizou a segunda edição da pesquisa intitulada "Carência de Profissionais". Averiguou-se que a escassez de mão de obra qualificada é um dos maiores problemas da economia brasileira, principalmente na indústria e no comércio. Em relação às regiões que possuem maior demanda por profissionais qualificados, encontra-se em primeiro lugar a região Sudeste (84\%), em seguida, Sul (47\%), Nordeste (41\%), Centro-Oeste (26\%), Norte (17\%) e, por fim, no exterior do país, com índice de 16\% (RESENDE; SOUSA, 2013).

De acordo com Barbosa (2013), o novo perfil profissional surge da tendência de um sistema de produção mais enxuto e flexível. O indivíduo deve ter habilidade de "incorporar e aportar seus conhecimentos aos processos de produção, participando da análise e solução de problemas que possam interferir no aumento da produtividade, qualidade e competitividade da empresa" (BARBOSA, 2013, p. 59).

Lojkine (1995 apud ARRUDA; MARTELETO; SOUZA, 2000) caracteriza o perfil do trabalhador de um novo modelo como íntegro e interativo com os processos da organização, superando a divisão consagrada entre os que projetam e os que desempenham o trabalho.

O mercado demanda, portanto, um novo perfil, um trabalhador que saiba agir, mobilizar recursos, integrar saberes múltiplos e complexos, com capacidade de aprender, engajar-se, arcar com responsabilidades e ter visão estratégica, características de um profissional competente (FLEURY M.; FLEURY A., 2001).

Para formar profissionais com o perfil demandado pelo mercado, Resende e Sousa (2013) relatam que a política de ensino do Brasil deve ser repensada de forma que gere mais 
conhecimento acadêmico e profissionalizante para atender as demandas da indústria de modo geral. "E essa geração de conhecimento precisa estar atrelada à busca constante da inovação. Esse é o capital humano necessário para que o Brasil dê um salto na qualidade de sua mão de obra” (RESENDE; SOUSA, 2013, p. 2).

A educação básica no país está estagnada em quantidade e qualidade de educação que os alunos adquirem. Compreende-se que o Brasil não está preparando indivíduos com as qualificações mínimas desejáveis para que exerçam a cidadania e sejam inseridos no mercado de trabalho (SCHWARTZMAN; CASTRO, 2013).

Para Catani, Oliveira e Dourado (2001, p. 77), “[...] só a formação de profissionais dinâmicos e adaptáveis às rápidas mudanças no mundo do trabalho e às demandas do mercado de trabalho poderá responder aos problemas de emprego e de ocupação profissional”. Nesse sentido, os autores evidenciam a necessidade de flexibilização/adaptação curricular para os cursos de graduação e apontam os princípios orientadores empregados para as mudanças curriculares nos cursos de graduação a partir da reforma curricular pela SESu/MEC por meio do Edital $n^{\circ} 4$, de 4 de dezembro de 1997. Entre os elementos propostos estão: adaptação às demandas do mercado de trabalho e definição e desenvolvimento de competências e habilidades gerais (CATANI; OLIVEIRA; DOURADO; 2001).

\subsection{A cidade de Formiga e suas instituições de ensino}

Formiga é uma cidade situada na mesorregião do Oeste de Minas de Gerais. Possui economia diversificada e apresenta algumas aglomerações produtivas. De acordo com o Instituto Brasileiro de Geografia e Estatística (IBGE) (2016), a economia da cidade é composta pelos setores agropecuário, industrial e de serviço/comércio. O municipal (valores de 2015) equivale a cerca de $\mathrm{R} \$ 863.736,00$. Em 2015, na última divulgação da participação dos setores no PIB, o ramo que apresentava maior participação era o de serviços/comércio, com aproximadamente 72,3\% (R \$624.670) do total. Em segundo lugar, estava a indústria com 21,1\% (R \$182.271) e, por último, o setor agropecuário com 6,6\% ( $\$ 56.795)$.

Ainda, segundo levantamento realizado pelo IBGE (2016), aproximadamente 19.810 indivíduos compõem a população ocupada que trabalham nas mais de 6000 empresas e organizações existentes na cidade, auferindo, para tanto, um salário médio mensal de cerca de 1,8 salários mínimos. 
Para proporcionar um contingente de mão de obra qualificada, a cidade conta com instituições de ensino médio/técnico e superior. Se alinhadas com as necessidades específicas de mão de obra da cidade, tais instituições podem potencializar as vocações produtivas de Formiga, proporcionando às empresas recurso humano qualificado, assegurando um diferencial competitivo para a cidade e região. Dentre as instituições de ensino mencionadas destacam-se IFMG - campus Formiga, UNIFOR e UAB.

\subsubsection{IFMG - Campus Formiga}

O IFMG - Campus Formiga é uma instituição pública federal que tem o objetivo de oferecer uma educação gratuita de qualidade. A instituição busca formar profissionais qualificados, comprometidos com a construção de uma sociedade mais justa e igualitária, além de gerar, transmitir e disseminar conhecimentos científicos, tecnológicos, artísticos e culturais, por meio do ensino, pesquisa e da extensão (INSTITUTO FEDERAL DE MINAS GERAIS, 2015).

O campus oferece cinco cursos superiores: Administração, Ciência da Computação, Engenharia Elétrica, Gestão Financeira e Matemática (Licenciatura), além de três cursos técnicos em Administração, Informática e Eletrotécnica (INSTITUTO FEDERAL DE MINAS GERAIS, 2015).

\subsubsection{UNIFOR-MG}

O Centro Universitário de Formiga (UNIFOR-MG) iniciou sua história em 1963 com a origem da Fundação Universidade do Oeste de Minas e hoje oferece vinte e dois cursos superiores, conforme descrito no Quadro 1 (CENTRO UNIVERSITÁRIO DE FORMIGA, 2015a; CENTRO UNIVERSITÁRIO DE FORMIGA, 2015b) 
VILELA, N.; TONELLI, A. O.; MASCARENHAS, I. F. Mão de obra qualificada na cidade de Formiga-MG: uma comparação entre os cursos oferecidos pelas IES e a demanda das empresas da cidade

\begin{tabular}{|ccc|}
\hline & Cursos oferecidos no UNIFOR-MG & \\
\hline Administração & Educação Física (Bacharelado) & Estética \\
Arquitetura e Urbanismo & Educação Física (Licenciatura) & Fisioterapia \\
Biblioteconomia & Enfermagem & Marketing \\
Biomedicina & Engenharia Agronômica & Medicina Veterinária \\
Ciências Biológicas & Engenharia Ambiental e Sanitária & Pedagogia (Docência) \\
Ciência da Computação & Engenharia Civil & Serviço Social \\
Ciências Contábeis & Engenharia de Produção & \\
Direito & Engenharia Química & \\
\hline
\end{tabular}

Quadro 1 - Relação dos 22 cursos superiores oferecidos pelo UNIFOR - MG

Fonte: Adaptado de Centro Universitário de Formiga (2015a).

\subsubsection{UAB}

A Universidade Aberta do Brasil (UAB) foi instituída pelo Decreto 5.800 de 8 de junho de 2006 e é voltada "para o desenvolvimento da modalidade de educação a distância, com a finalidade de expandir e interiorizar a oferta de cursos e programas de educação superior no País" (BRASIL, [201_]a; BRASIL, [201_]b).

No polo da cidade de Formiga, são ofertados os seguintes cursos: Administração Pública Universidade Federal de Lavras (UFLA), Ciências Biológicas Universidade Federal de Alfenas (UNIFAL), Filosofia Universidade Federal de São João Del Rei (UFSJ), Geografia Universidade Federal de Minas Gerais (UFMG), Matemática (UFSJ) e Pedagogia (UFMG) (BRASIL, [201_]a; BRASIL, [201_]a).

\section{METODOLOGIA}

Quanto à abordagem da pesquisa, atribui-se a forma quali-quanti. Em relação aos objetivos, é exploratória e descritiva e no que diz respeito aos procedimentos, a pesquisa caracteriza-se como survey.

O universo da pesquisa é a cidade de Formiga-MG e a amostra não probabilística, por acessibilidade e/ou conveniência consistiu de 56 empresas da cidade associadas à Associação Comercial, Industrial, de Serviços e Agronegócios de Formiga (ACIF) e Câmara de Dirigentes Lojistas de Formiga (CDL). 
O método utilizado na coleta de dados foi o questionário (disposto no Apêndice A), que, além de questões básicas de caracterização da empresa, buscou identificar os níveis de escolaridade exigidos para as contratações, os cargos exercidos pelos funcionários para cada nível de escolaridade e os conhecimentos e habilidades que os colaboradores devem ter para desempenhar o cargo.

Por último, os dados foram analisados por meio da análise de conteúdo nas questões qualitativas, e, nas questões quantitativas, de caracterização da empresa, foram utilizadas distribuições de frequência.

\section{RESULTADOS E DISCUSSÕES}

\subsection{Caracterização das empresas}

As análises foram realizadas a partir de 56 questionários aplicados em empresas na cidade de Formiga-MG com diretores, proprietários, sócios, gerentes e analistas em recursos humanos das empresas. A maioria das empresas entrevistadas é de micro e pequeno porte (Tabela 2) e atuantes principalmente nos setores de comércio e prestação de serviços (Tabela 3). Em relação ao número de funcionários, 64,29\% das empresas possuem menos que 19 colaboradores (Tabela 4). Os ramos de atividade das organizações são diversificados, incluindo agropecuária, alimentos, calçados e acessórios, componentes eletrônicos, confecção, consultoria, cosméticos, hospitalar, material de construção, panificação, peças e acessórios para bicicletas e motos, revenda de combustíveis, segurança, tintas e complementos, veículos e peças, entre outros.

Tabela 2 - Porte das empresas entrevistadas - Formiga (MG) - 2015

\begin{tabular}{lcc}
\hline \multicolumn{1}{c}{ Porte da empresa } & Frequência & Porcentagem \\
\hline Micro e Pequena Empresa & 36 & $64,29 \%$ \\
Médio & 16 & $28,57 \%$ \\
Grande & 4 & $7,14 \%$ \\
\hline
\end{tabular}

Fonte: Dos autores (2016). 
VILELA, N.; TONELLI, A. O.; MASCARENHAS, I. F. Mão de obra qualificada na cidade de Formiga-MG: uma comparação entre os cursos oferecidos pelas IES e a demanda das empresas da cidade

Tabela 3 - Segmento de atuação das empresas entrevistadas - Formiga (MG) - 2015

\begin{tabular}{lcc}
\multicolumn{1}{c}{ Segmento que a empresa atua } & Frequência & Porcentagem \\
\hline Comércio & 29 & $51,79 \%$ \\
Prestação de Serviços & 16 & $28,57 \%$ \\
Indústria & 7 & $12,50 \%$ \\
Comércio/ Prestação de Serviços & 3 & $5,36 \%$ \\
Indústria/ Prestação de Serviços & 1 & $1,79 \%$ \\
\hline
\end{tabular}

Fonte: Dos autores (2016).

Tabela 4 - Número agrupado de funcionários das empresas entrevistadas

\begin{tabular}{lcc}
\multicolumn{1}{c}{ Número de funcionários } & Frequência & Porcentagem \\
\hline Menor que 9 & 19 & $33,93 \%$ \\
De 10 a 19 & 17 & $30,36 \%$ \\
De 20 a 49 & 12 & $21,43 \%$ \\
De 50 a 99 & 4 & $7,14 \%$ \\
De 100 a 499 & 3 & $5,36 \%$ \\
$>500$ & 1 & $1,79 \%$ \\
\hline
\end{tabular}

Fonte: Dos autores (2016).

\subsection{Escolaridade e Qualificação}

Quando questionadas a respeito do nível de escolaridade exigido para contratação, percebe-se que quase metade das empresas da amostra demandam colaboradores com ensino fundamental e 75\% das empresas admitem indivíduos com segundo grau completo (Tabela 5), o que, segundo Dias (2013), são, predominantemente, profissionais menos qualificados, sendo considerados qualificados os que estudaram mais que 11 anos, ou seja, aqueles que possuem graduação e pós-graduação. Por outro lado, 20 empresas $(35,71 \%)$ mencionaram admitir alguém com nível superior, e apenas uma assinalou a opção de pós-graduação (Tabela 5).

Tabela 5 - Nível de escolaridade exigido pelas empresas entrevistadas - Formiga (MG) - 2015

\begin{tabular}{lll}
\hline Nível de escolaridade exigido & Frequência & Porcentagem \\
\hline Fundamental & 27 & $48,21 \%$ \\
Médio & 42 & $75,00 \%$ \\
Técnico & 16 & $28,57 \%$ \\
Superior & 20 & $35,71 \%$ \\
Pós-Graduação & 1 & $1,79 \%$ \\
Não exige & 1 & $1,79 \%$ \\
\hline
\end{tabular}

Fonte: Dos autores (2016).

Nota: as empresas respondentes assinalaram os níveis de escolaridade exigidos para contratação em diferentes cargos. Tais níveis tiveram variação de um cargo para outro, ainda que na mesma empresa. Por essa razão, a frequência acumulada não é igual ao número de empresas entrevistadas. 
$\mathrm{O}$ fato de grande parte das empresas entrevistadas contratar profissionais com baixo nível de escolaridade condiz com a proposição de Schwartzman e Castro (2013). Os autores consideram que existe a possibilidade de a economia brasileira estar acomodada com um baixo padrão de qualificação de mão de obra e produtividade. Esse padrão reduzido pode estar relacionado ao fato de que profissionais mais qualificados requerem salários mais elevados e pode ser comprovado pela afirmativa de um respondente, sócio proprietário de uma empresa pertencente da amostra, quando questionado sobre a necessidade de abertura de novos cursos superiores em Formiga-MG: "[...] precisa-se de colaboradores com certo grau de formação, mas eleva a despesa da empresa, pois exigem-se (sic) salários altos, o que não condiz com a atual situação do país".

Quanto à ausência de mão de obra qualificada, 50\% das empresas pesquisadas confirmaram que essa é uma dificuldade encontrada na gestão da empresa. No entanto, ao realizar uma frequência cruzada entre as empresas que relataram ausência de mão de obra qualificada e as que contratam profissionais menos qualificados, ou seja, aqueles que não possuem ensino superior, nota-se que 64,28\% (18) das empresas que se queixam da mão de obra desqualificada não contratam indivíduos qualificados, tendo em seus ambientes organizacionais profissionais com ensino fundamental e/ou médio e/ou técnico.

\subsection{Cargos e habilidades requeridas dos colaboradores}

Os cargos existentes nas empresas entrevistadas foram agrupados de acordo com o nível de escolaridade que o indivíduo deve ter para ocupá-los e elencados da seguinte forma: 28 são referentes ao nível fundamental, 35 ao médio, 16 correspondem ao nível técnico, 20 ao superior e apenas 1 relaciona-se com a pós-graduação.

O Quadro 2 explicita todos os cargos que foram mencionados como exercidos por profissionais com ensino fundamental. As habilidades requeridas desses funcionários foram principalmente experiência, atenção, bom desempenho e organização. 
VILELA, N.; TONELLI, A. O.; MASCARENHAS, I. F. Mão de obra qualificada na cidade de Formiga-MG: uma comparação entre os cursos oferecidos pelas IES e a demanda das empresas da cidade

\begin{tabular}{|ccc|}
\hline & Cargos - Ensino Fundamental & \\
\hline Acabamento & Balconista & Manutenção geral \\
Ajudante & Cabeleireira & Mecânico \\
Atendente & Cobrador & Mesária \\
Auxiliar de cozinha & Costureira & Oficina \\
Auxiliar de padeiro & Entregador & Pedreiro \\
Auxiliar de produção & Frentista & Pintor \\
Auxiliar de serviços & Instrutor de autoescola & Plantonista \\
gerais & & \\
Auxiliar de torneiro & Lavador & Servente \\
mecânico & Manicure & Soldador \\
Auxiliar funilaria & & Vendedor \\
\end{tabular}

Quadro 2 - Cargos exercidos por profissionais com Ensino Fundamental

Fonte: Dos autores (2016).

Alguns cargos mencionados necessitam de conhecimentos mais específicos. Os cobradores e entregadores, por exemplo, precisam ter habilidade de comunicação e carteira de habilitação. A balconista deve ter noções de Administração; do frentista é requerido manuseio com dinheiro (troco), máquinas de cartão de crédito/débito e produtos tóxicos; o auxiliar de padeiro necessita ter destreza manual, criatividade e saber trabalhar em equipe.

Apesar de a maioria das ocupações serem vinculadas a conhecimentos condizentes tanto com o cargo quanto com o nível de escolaridade (a título de exemplo, o instrutor de autoescola deve ter feito curso de direção), alguns cargos elencados no Quadro 2 requisitam competências além das esperadas por um indivíduo com formação básica.

Uma empresa do ramo alimentício demanda do auxiliar de cozinha conhecimentos de tarefas da área de faturamento, gerenciamento da produção, habilidade de comunicação, noções de matemática comercial e financeira, pesquisa de mercado e técnicas de negociação e vendas. No mesmo sentido, uma empresa de enxovais e persianas contrata vendedores que conhecem e operam ferramentas de informática básica, possuem conhecimentos em estratégias de compra e venda, marketing, logísticos e de estoque, tarefas da área de faturamento, gerenciamento de contas a pagar e a receber, tenham habilidade de comunicação, noções de administração e técnicas de negociação e vendas. Percebe-se, portanto, que apesar de não ocorrer com muita frequência, um número de cargos exige capacidades e aptidões incompatíveis com a ocupação e escolaridade dos indivíduos. 
VILELA, N.; TONELLI, A. O.; MASCARENHAS, I. F. Mão de obra qualificada na cidade de Formiga-MG: uma comparação entre os cursos oferecidos pelas IES e a demanda das empresas da cidade

Quanto ao ensino médio, os cargos estão expostos no Quadro 3. Para esse nível de escolaridade, as habilidades mais mencionadas foram experiência, boa comunicação e conhecer e operar ferramentas de informática básica (editores de texto e planilha).

\begin{tabular}{|ccc|}
\hline & Cargos - Ensino Médio & \\
\hline Ajudante de agrimensor & Caminhoneiro & Frentista \\
Atendente & Cobrador & Frentista caixa \\
Auxiliar administrativo & Consultor técnico & Gerente \\
Auxiliar contabilidade & Costureira & Manicure \\
Auxiliar de escritório & Depósito & Mecânico \\
Auxiliar de produção & Eletricista & Mesária \\
Auxiliar de serralheiro & Eletrotécnico & Motoboy \\
Auxiliar financeiro & Embalador & Motorista \\
Balconista & Encarregado de obras & Prestador de serviços \\
Cabeleireira & Entregador & gerais \\
Caixa & Estoquista & Recepção \\
& & Trocador de óleo \\
& & Vendedor \\
\hline
\end{tabular}

Quadro 3 - Cargos exercidos por profissionais com Ensino Médio

Fonte: Dos autores (2016).

Para os cargos de auxiliares administrativo, contabilidade, de escritório, financeiro e caixa são exigidos conhecimentos específicos de administração como recursos humanos e gestão de pessoas, noções de matemática comercial e financeira, conhecimentos aprofundados em contabilidade, análise financeira e orçamentos, arquivamento, rotinas contábeis, conhecimento de rotinas de compras e contratos, conhecimentos em legislação trabalhista, banco de dados e controle administrativo.

Para os demais cargos de nível médio, as aptidões são compatíveis com o nível de escolaridade do profissional, por exemplo, para ser motoboy, o indivíduo deve ter habilitação, direção defensiva, atenção, expertise e noção de endereços na cidade. As ocupações de atendente, balconista e recepção requerem cordialidade e proatividade. Por fim, os vendedores devem conhecer as técnicas de negociação e vendas, ter iniciativa e trabalhar em equipe.

Nos cargos em que são exigidos curso técnico (Quadro 4) e curso superior (Quadro 5), as habilidades e qualificações dos indivíduos parecem estar em conformidade tanto com o cargo quanto com o grau de escolaridade. 
VILELA, N.; TONELLI, A. O.; MASCARENHAS, I. F. Mão de obra qualificada na cidade de Formiga-MG: uma comparação entre os cursos oferecidos pelas IES e a demanda das empresas da cidade

\begin{tabular}{ccc}
\hline & Cargos - Ensino Técnico & \\
\hline Agrimensor & Enfermeiro & Mecânico \\
Auxiliar contabilidade & Esteticista & Pintor \\
Auxiliar de escritório & Gerente de pista & Qualidade/Laboratório \\
Auxiliar de laboratório & Instalador & Secretária \\
Auxiliar de serralheiro & Lanterneiro & Segurança do trabalho \\
& & Tecnólogo em alimentos \\
\hline Quadro 4- Cargos exercidos por profissionais com Ensino Técnico & \\
Fonte: Dos autores (2016). & & \\
& & \\
& & Cargos - Ensino Superior \\
Administrador & Consultor & Gerente \\
Analista & Coordenador & Professor \\
Analista de RH & Designer & Psicólogo \\
Assistente administrativo & Diretor & Secretária \\
Auxiliar de escritório & Enfermeiro & Supervisor \\
Bioquímico & Engenheiro & Vendedor \\
Caixa & Esteticista &
\end{tabular}

Quadro 5 - Cargos exercidos por profissionais com Ensino Superior

Fonte: Dos autores (2016).

Por último, o único cargo para profissionais com pós-graduação dentre as empresas pesquisadas é o de gestor da qualidade. Para exercer tal função, o colaborador deve ter conhecimentos em arquivamento, avaliação de desempenho, ferramentas de informática básica, comércio eletrônico, gestão de custos, programação, estatística, marketing, tarefas da área de faturamento, gerenciar a produção, habilidade de comunicação, noções de administração e contabilidade, orçamento e planejamento, pesquisa de mercado e trabalhar com banco de dados.

\subsection{Demanda de cursos superiores}

Grande parte dos cursos relacionados aos cargos e aos conhecimentos e habilidades requeridas dos profissionais demandados pelas empresas de Formiga é oferecida nas três instituições de ensino superior.

No entanto, ainda há procura por profissionais de alguns cursos não disponíveis na cidade como Bioquímica, Design Gráfico, Engenharia Mecânica, Farmácia, Gestão Comercial, Gestão de Recursos Humanos e Psicologia. O Quadro 7 mostra os cargos 
VILELA, N.; TONELLI, A. O.; MASCARENHAS, I. F. Mão de obra qualificada na cidade de Formiga-MG: uma comparação entre os cursos oferecidos pelas IES e a demanda das empresas da cidade

exercidos por profissionais de nível superior, os conhecimentos e habilidades que esses devem possuir e os cursos superiores que possuem relação.

\begin{tabular}{|c|c|c|}
\hline Cargos & Conhecimentos/ Habilidades & Cursos relacionados \\
\hline $\begin{array}{l}\text { Administrador, } \\
\text { Consultor, Gerente, } \\
\text { Supervisor }\end{array}$ & $\begin{array}{l}1,3,7,13,16,23,24,34^{*}, \\
\text { conhecimento gestão, processos, } \\
\text { liderança, comunicação, visão } \\
\text { sistêmica }\end{array}$ & Administração \\
\hline $\begin{array}{l}\text { Analista, Analista de } \\
\text { RH, Coordenador }\end{array}$ & $\begin{array}{l}\text { Experiência de } 6 \text { meses na área, visão } \\
\text { estratégica, coerência, iniciativa, } 1,4 \text {, } \\
9,13,14,16,18,20,21,22,25,29,30 \text {, } \\
32\end{array}$ & $\begin{array}{l}\text { Administração, Ciências } \\
\text { Contábeis, Gestão de Recursos } \\
\text { Humanos }\end{array}$ \\
\hline $\begin{array}{l}\text { Assistente adm., Aux. } \\
\text { de escritório, Caixa, } \\
\text { Diretor, Secretária }\end{array}$ & $\begin{array}{l}1,2,3,4,5,12,16,17,18,20,21,22 \\
23,24,25,26,29,30,31\end{array}$ & $\begin{array}{l}\text { Administração, Ciências } \\
\text { Contábeis, Gestão Financeira }\end{array}$ \\
\hline Bioquímico & - & Bioquímica \\
\hline Designer & Softwares específicos & Design Gráfico, Marketing \\
\hline Enfermeiro & $\begin{array}{l}\text { Comunicação, atenção, trabalho em } \\
\text { equipe, expertise }\end{array}$ & Enfermagem \\
\hline Engenheiro & $\begin{array}{l}1,4,5,7,16,17,18,20,21,22,23,26 \\
29,31,32,33,34^{*}\end{array}$ & $\begin{array}{l}\text { Engenharias: Ambiental e } \\
\text { Sanitária, Civil, de Produção, } \\
\text { Elétrica, Mecânica, Química }\end{array}$ \\
\hline Esteticista & $-* *$ & Estética \\
\hline Farmacêutico & $-* *$ & Farmácia \\
\hline Professor & $-* *$ & Pedagogia \\
\hline Psicólogo & $-* *$ & Psicologia \\
\hline Vendedor & $4,15,33,34$ & $\begin{array}{l}\text { Tecnologia em Gestão } \\
\text { Comercial }\end{array}$ \\
\hline
\end{tabular}

Quadro 6 - Relação entre cargos, conhecimento/ habilidades e cursos superiores

Fonte: Dos autores (2016).

Nota: *As referências numéricas presentes no quadro estão especificadas no Quadro de referência para conhecimentos/ habilidades apresentado no Apêndice A.

**Os conhecimentos/habilidades dos cargos: bioquímico, esteticista, farmacêutico, professor e psicólogo não foram preenchidos pelos entrevistados.

\section{CONCLUSÕES}

A escassez de mão de obra qualificada é um grande problema na economia brasileira, principalmente na indústria e no comércio e intensifica-se quando se trata de micro, pequenas e médias empresas. O conceito de mão de obra qualificada está intimamente associado à escolaridade, sendo considerados qualificados aqueles que possuem escolaridade superior a 11 anos, ou seja, que iniciaram ou concluíram cursos de graduação e pós-graduação. 
A cidade de Formiga, localizada no centro-oeste de Minas Gerais, possui 72,3\% do PIB baseado no setor de serviços/comércio, e conta com instituições de ensino médio/técnico e superior para oferecer profissionais qualificados que atendam à demanda das empresas locais. Dessas instituições, três proporcionam cursos de nível superior e o objetivo da pesquisa foi identificar se os cursos de graduação oferecidos na cidade atendem à demanda das empresas por mão de obra qualificada.

Foram entrevistadas 56 empresas formiguenses de micro, pequeno, médio e grande porte. Constatou-se que a maioria das empresas admite indivíduos considerados desqualificados, ou seja, apenas com níveis de escolaridade fundamental e médio. Aproximadamente $36 \%$ da amostra empregam profissionais com nível superior e grande parte dos cargos exercidos por esses estão relacionados a cursos superiores oferecidos pelas IES de Formiga, como Administração, Ciências Contábeis, Enfermagem, Engenharias, Estética, Gestão Financeira, Marketing e Pedagogia. Ainda assim, profissionais dos cursos de Bioquímica, Design Gráfico, Engenharia Mecânica, Farmácia, Gestão Comercial, Gestão de Recursos Humanos e Psicologia foram apontados como requeridos pelas empresas entrevistadas.

Apesar de ter sido identificada a demanda por sete novos cursos superiores, a pesquisa revelou que a maioria das empresas contrata trabalhadores com escolaridade inferior a 11 anos, mas também busca características de profissionais qualificados, exigindo que esses possuam habilidades e conhecimentos além do esperado para o nível de formação dos mesmos. Isso ocorre devido ao fato de que profissionais qualificados exigem salários mais elevados. Além disso, a economia brasileira contenta-se com baixos padrões de qualificação de mão de obra e produtividade, contribuindo para que cada vez mais profissionais desqualificados "substituam" os qualificados (SCHWARTZMAN; CASTRO, 2013).

As limitações deste trabalho reportam-se principalmente à metodologia. Primeiramente, pelo tamanho da amostra e a quantidade de empresas de cada porte (micro e pequena, média e grande). Outra limitação é relacionada aos critérios de conveniência adotados para a escolha das empresas entrevistadas, o que impossibilita generalizar os resultados para todas as empresas da cidade. 
APÊNDICE A - Questionário

1. Segmento em que a empresa atua:
( ) Comércio
( ) Indústria
( ) Prestação de serviços

2. Ramo de atividade:

3. Porte da empresa:
( ) Microempresa
( ) Pequena
( ) Média
( ) Grande

4. Número de colaboradores:
$(\quad)<9$
( ) De 10 a 19
( ) De 20 a 49
( ) De 50 a 99
( ) De 100 a 499
$>500$

5. Quais os níveis de escolaridade exigidos pela empresa em suas contratações no último ano? Caso necessário assinale mais de um nível.
( ) Fundamental
( ) Médio
( ) Técnico
( ) Superior
( ) Pós-graduação

6. Para cada nível de escolaridade assinalado na questão anterior, defina o cargo a ser ocupado pelo profissional contratado:

\begin{tabular}{|l|l|}
\hline Nível de escolaridade & Cargos \\
\hline & \\
\hline & \\
\hline & \\
\hline
\end{tabular}

7. Para cada cargo elencado na questão anterior, descreva quais os principais conhecimentos/habilidades necessários aos colaboradores para exercer tal função: (Caso necessário, utilize o quadro disposto no final do questionário)

\begin{tabular}{|l|l|}
\hline Cargo & Conhecimentos/ Habilidades \\
\hline & \\
\hline & \\
\hline & \\
\hline
\end{tabular}


VILELA, N.; TONELLI, A. O; MASCARENHAS, I. F. Mão de obra qualificada na cidade de Formiga-MG: uma comparação entre os cursos oferecidos pelas IES e a demanda das empresas da cidade

8. Além das opções já oferecidas pelas instituições de ensino da cidade, existem outros cursos de nível superior que poderiam formar profissionais que atenderiam às demandas de sua empresa? Se sim, qual (is)?

\section{A ausência de mão de obra qualificada pode ser considerada uma dificuldade} encontrada na gestão da empresa?

( ) $\operatorname{Sim} \quad$ ( ) Não

Quadro de referência para conhecimentos/habilidades

\begin{tabular}{|c|c|c|c|}
\hline Referência & Conhecimento/habilidade & Referência & Conhecimento/habilidade \\
\hline 1 & Análise financeira e orçamentos & 18 & $\begin{array}{l}\text { Conhecimentos de tarefas da área de faturamento } \\
\text { (emissão de Notas Fiscais, recibos, etc) }\end{array}$ \\
\hline 2 & Arquivamento & 19 & Gerenciar a Produção \\
\hline 3 & Avaliação de desempenho & 20 & Gerenciar as contas a pagar e a receber \\
\hline 4 & $\begin{array}{l}\text { Conhecer e operar ferramentas de } \\
\text { informática básica (editores de texto e } \\
\text { planilhas) }\end{array}$ & 21 & Gerenciar o capital de giro \\
\hline 5 & Conhecer rotinas de compras e contratos & 22 & Habilidade de comunicação \\
\hline 6 & Conhecimento em comércio eletrônico & 23 & Noções de Administração \\
\hline 7 & Conhecimento em gestão de custos & 24 & Noções de Contabilidade \\
\hline 8 & Conhecimento em programação & 25 & Noções de Matemática comercial e Financeira \\
\hline 9 & $\begin{array}{l}\text { Conhecimentos aprofundados em } \\
\text { Contabilidade }\end{array}$ & 26 & Orçamento e planejamento \\
\hline 10 & Conhecimentos em Economia & 27 & Pesquisa de mercado \\
\hline 11 & Conhecimentos em Estatística & 28 & Plano de cargos e salários \\
\hline 12 & $\begin{array}{l}\text { Conhecimentos em Estratégias de } \\
\text { compra e venda }\end{array}$ & 29 & Recrutamento e seleção \\
\hline 13 & Conhecimentos em legislação trabalhista & 30 & Rotinas contábeis \\
\hline 14 & Conhecimentos em legislação tributária & 31 & Rotinas financeiras \\
\hline 15 & Conhecimentos em marketing & 32 & Rotinas trabalhistas \\
\hline 16 & $\begin{array}{l}\text { Conhecimentos em RH e gestão de } \\
\text { pessoas }\end{array}$ & 33 & Técnicas de negociação e vendas \\
\hline 17 & Conhecimentos logísticos e de estoque & 34 & Trabalhar com banco de dados \\
\hline
\end{tabular}


VILELA, N.; TONELLI, A. O.; MASCARENHAS, I. F. Mão de obra qualificada na cidade de Formiga-MG: uma comparação entre os cursos oferecidos pelas IES e a demanda das empresas da cidade

\title{
MANPOWER QUALIFIED IN FORMIGA-MG CITY: A COMPARISON BETWEEN COURSES OFFERED BY IES AND DEMAND OF CITY ENTERPRISES
}

\begin{abstract}
The lack of manpower is a problem occurring in the Brazilian economy. This difficulty is enhanced in the micro, small and medium enterprises (MSEs), often because they are newer companies without prior planning. This study aimed to explore the relationship between the supply of higher education in Formiga-MG and demand of local enterprises by qualified professionals. The research, qualitative and exploratory character had a participation of 56 municipal companies, being 36 micro and small, operating in different segments. The results showed that companies choose to hire professionals with low education level (less than 11 years), but often seek qualified professional features. In addition, less than half of interviewees mentioned admit professionals with higher education level, and admits employed who has only graduation. This may be a result of the Brazilian economy accommodation over the low workforce qualification standards and productivity.
\end{abstract}

Keywords: Professional qualification. Job market. Higher education.

\section{REFERÊNCIAS}

ARRUDA, M. C. C.; MARTELETO, R. M.; SOUZA, D. B. Educação, trabalho e o delineamento de novos perfis profissionais: o bibliotecário em questão. Ciência da Informação, v. 29, n. 3, p. 14-24, set./dez. 2000.

BARBOSA, J. O. O "GAP” entre o perfil profissional dos estudantes formados pelo CefetMT e as demandas do mercado de trabalho. Profiscientia, n. 4, nov. 2013.

BRASIL. Ministério da Educação. Fundação Capes. Universidade Aberta do Brasil. Polo UAB: Formiga - Rosário (Formiga - MG). Brasília, [201_]. Disponível em:

$<$ https://sisuab.capes.gov.br/sisuab/PesquisasUAB/Polo_show.action?id=97>. Acesso em: 14 fev. 2016a.

Ministério da Educação. Fundação Capes. Universidade Aberta do Brasil. Sobre a

UAB. Brasília: [201_]. Disponível em: <http://www.uab.capes.gov.br/index.php/comp onent/content/article?id=6>. Acesso em: 14 fev. 2016 b.

CASTELLO BRANCO, R. C. Crescimento acelerado e o mercado de trabalho: a experiência brasileira. Rio de Janeiro: Fundação Getúlio Vargas, 1979. Disponível em: $<$ http://bibliotecadigital.fgv.br/dspace/bitstream/handle/10438/13065/000012777.pdf?sequenc $\mathrm{e}=1$ \&isAllowed $=\mathrm{y}>$. Acesso em: 16 abr. 2015. 
CATANI, A. M.; OLIVEIRA, J. F.; DOURADO, L. F. Política educacional, mudanças no mundo do trabalho e reforma curricular dos cursos de graduação no Brasil. Educação e Sociedade, v. 22, n. 75, p. 67-83, ago. 2001.

CENTRO UNIVERSITÁRIO DE FORMIGA. Graduação. Formiga, 2015. Disponível em: $<$ http://www.uniformg.edu.br/index.php/graduacao $>$. Acesso em: 13 abr. 2015a.

História. Formiga, 2015. Disponível em:

$\overline{<h t t p: / / w w w . u n i f o r m g . e d u . b r / i n d e x . p h p / i n s t i t u c i o n a l / h i s t o r i a>. ~ A c e s s o ~ e m: ~} 13$ abr. 2015b.

DIAS, J. Desafios da Qualificação no Brasil: demandas dos setores tradicionais e tecnológicos de curto e longo prazo por mão-de-obra qualificada. In: ENCONTRO NACIONAL DE ECONOMIA. 41., 2013, Foz do Iguaçu. Anais... Foz do Iguaçu: ANPEC, 2013.

CONFEDERAÇÃO NACIONAL DO COMÉRCIO DE BENS, SERVIÇOS E TURISMO. Empresômetro MPE. 2016. Disponível em: <http://empresometro.cnc.org.br/Estatisticas>. Acesso em: 17 fev. 2016.

FLEURY, M. T. L.; FLEURY, A. Construindo o conceito de competência. Revista de Administração Contemporânea, v. 5, n. spe, p. 183-196, 2001.

FRACALANZA, P. S.; FERREIRA, A. N.. Micro e Pequenas Empresas: rotatividade da força de trabalho e implicações para o desenvolvimento no Brasil. In: SANTOS, Anselmo Luís dos; KREIN, José Dari; CALIXTRE, André Bojikian (Orgs.). Micro e Pequenas Empresas: mercado de trabalho e implicação para o desenvolvimento. Rio de Janeiro: IPEA, 2012, p. 89112.

FUNDAÇÃO DOM CABRAL. Pesquisa Carência de Profissionais. Belo Horizonte: FDC, 2010 .

Pesquisa Carência de Profissionais. Belo Horizonte: FDC, 2013.

IAROZINSKI NETO, A.; CACIATORI JUNIOR, I. Classificação das principais dificuldades enfrentadas pelas pequenas e médias empresas (PMEs). In: SIMPEP. 13., 2006, Bauru.

Anais... Bauru: UNESP, 2006. Disponível em: $<$ http://www.simpep.feb.unesp.br/anais/anais _13/artigos/539.pdf>. Acesso em: 17 abr. 2015.

INSTITUTO BRASILEIRO DE GEOGRAFIA E ESTATÍSTICA. As Micro e pequenas empresas comerciais e de serviços no Brasil: 2001. Rio de Janeiro: IBGE, 2003.

IBGE Cidades - Formiga. 2016. Disponível em:

$\overline{<h t t p: / / w w w . c i d a d e s . i b g e . g o v . b r />. ~ A c e s s o ~ e m: ~} 10$ fev. 2016.

INSTITUTO FEDERAL DE MINAS GERAIS. Histórico: campus Formiga. Formiga: 2015. Disponível em: <www.formiga.ifmg.edu.br>. Acesso em: 10 abr. 2015. 
RESENDE, P. T. V.; SOUSA, P. R. Carência de profissionais: um desafio para as grandes empresas brasileiras. [S.1]: Fundação Dom Cabral, 2013.

SCHWARTZMAN, S.; CASTRO, C. M. Ensino, formação profissional e a questão da mão de obra. Ensaio: Avaliação e Políticas Públicas em Educação, v. 21, n. 80, p. 563-624, jul./set. 2013.

SERVIÇO BRASILEIRO DE APOIO ÀS MICRO E PEQUENAS EMPRESAS. Micro e Pequenas Empresas geram 27\% do PIB do Brasil. 2014. Disponível em:

$<$ http://www.sebrae.com.br/sites/PortalSebrae/ufs/mt/noticias/Micro-e-pequenas-empresasgeram-27\%25-do-PIB-do-Brasil>. Acesso em: 12 abr. 2015a.

SERVIÇO BRASILEIRO DE APOIO ÀS MICRO E PEQUENAS EMPRESAS.

Participação das Micro e Pequenas Empresas na Economia Brasileira. 2014. Disponível em: <http://www.sebrae.com.br/Sebrae/Portal\%20Sebrae/Estudos\%20e\%20

Pesquisas/Participacao\%20das\%20micro\%20e\%20pequenas\%20empresas.pdf $>$. Acesso em: 12 abr. 2015b.

Recebido em: 15/06/2016

Aprovado em: 1\%09/2016

Publicado em: 11/10/2016 